\title{
Barriers to the Adoption of Improved Cooking Stoves for Rural Resilience and Climate Change Adaptation and Mitigation in Kenya
}

\author{
Daniel M. Nzengya, Paul Maina Mwari, and Chrocosiscus Njeru
}

\section{Contents}

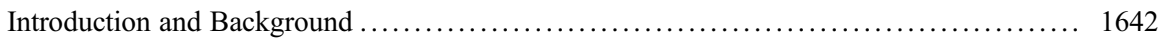

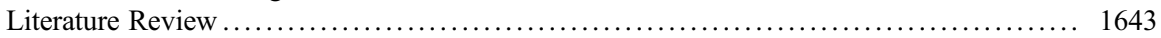

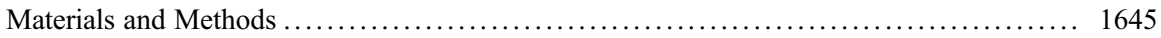

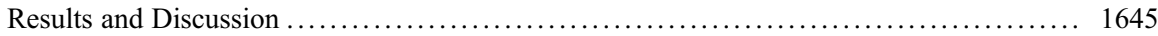

Sociodemographic Characteristics of the Sample ............................ 1645

Source of Energy for Cooking and Perceived Importance of Various Sources by Study

Sites ................................................................. 1645

Women's Perceptions of Health Risks Associated with Reliance on Firewood ......... 1650

Perceived Future Trends on Use of Various Forms of Energy Sources ............... 1651

Perceived Barriers to Adoption of Improved Cooking Stoves ...................... 1653

Lessons Learned, Study Limitations, and Recommendations for Future Research ......... 1657

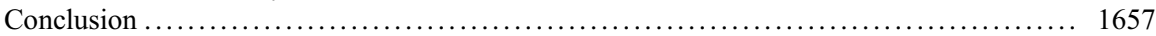

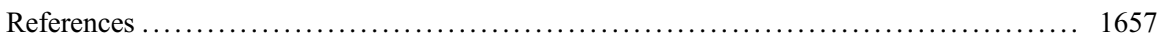

\begin{abstract}
Majority of Kenya's citizens reside in the rural areas where wood fuel is still the primary source of energy for cooking. Continuing reliance on wood fuel against the backdrop of burgeoning population poses huge threats to the country's forest cover, undermining capacity for climate change mitigation and adaptation. This study
\end{abstract}

This chapter was previously published non-open access with exclusive rights reserved by the Publisher. It has been changed retrospectively to open access under a CC BY 4.0 license and the copyright holder is "The Author(s)". For further details, please see the license information at the end of the chapter.

D. M. Nzengya ( $\square)$

Department of Social Sciences, St Paul's University, Limuru, Kenya

e-mail: dmuasya@spu.ac.ke

P. Maina Mwari · C. Njeru

Faculty of Social Sciences, St Paul's University, Limuru, Kenya

e-mail: mainapaul72@gmail.com; chrocnjeru@gmail.com 
conducted in Machakos and Laikipia counties explored; (i) women's perceptions of the health risks associated with dependence of firewood for cooking, (ii) women's attitudes and perceptions towards improved cooking charcoal stoves (ICS) as cleaner alternatives to traditional firewood stoves for cooking, and (iii) women's perceptions of barriers to adoption of improved cooking stoves. Study findings revealed that women were aware of the health risks associated with the use of firewood for cooking. However, despite these perceptions, upward trends in demands for firewood as a source of energy for cooking in the rural areas may persist in the next coming decades. Barriers to adoption of improved cooking stoves vary by sociocultural contexts. The study concludes that innovations that involve stakeholders especially participatory designs, monitoring, and evaluation of ICS might improve adoption levels. Moreover, innovations to increase adoption need to leverage on the opportunities provided by Sustainable development goal number 7 to accelerate adoption of ICS among other forms of cleaner, affordable, and sustainable sources of energy for cooking.

\section{Keywords}

Improved cooking stoves $\cdot$ Barriers to adoption $\cdot$ Rural resilience $\cdot$ Climate change mitigation $\cdot$ Women $\cdot$ Kenya

\section{Introduction and Background}

Sustainable development goal number seven, target 7.1 challenges the international development community and various governments to work towards achieving universal access to affordable, reliable, and modern energy services by 2030. It is estimated that about three billion people globally rely on biomass and coal burning for domestic use (WHO 2016). Majority of these population resides in developing nations (Clark et al. 2009). The solid biomass fuels available locally are such as wood, charcoal, dung, and agricultural residues for cooking, heating, and other domestic basic needs (Boampong and Phillips 2016). The emissions emanating from these energy sources pose health risks to humanity, among many other negative social and environmental impacts (Dickinson et al. 2015).

Ndegwa and others (2011) posit that $94 \%$ of the African rural population and $73 \%$ of urban population relay heavily on biomass energy especially for cooking and heating. They further state that wood fuel energy not only used as household energy but also used in schools, hospitals, colleges, small industries, and hotels. Women from rural areas and children below 5 years suffer most from health risks posed by biomass burning during long hours of cooking. The identified drivers of rising demands for wood fuel for cooking include, rapid population growth, inaccessibility to cheaper and affordable alternative energy substitutes, and the rising pervasive poverty and inequality.

Kenya has one of the largest rural populations that still rely on wood fuel as a primary source of energy for cooking. This preliminary study conducted Machakos and Laikipia counties explored; (i) women's perceptions of health risks and the 
socioenvironmental consequences associated with dependence of firewood for cooking, (ii) women's attitudes and perceptions towards improved cooking charcoal stoves as cleaner alternatives to traditional firewood stoves for cooking, and (iii) women's perceptions of barriers to adoption of improved cooking stoves by rural households.

\section{Literature Review}

Wood fuel is widely used in Kenya's rural areas and urban slums. It accounts for $68 \%$ of energy sources in the country with petroleum accounting for $22 \%$, electricity at $9 \%$, and coal at less than $1 \%$ (Ndegwa et al. 2011). It is estimated that biomass energy, firewood, charcoal, and agricultural wastes contributes approximately up to $70 \%$ of Kenya's energy demand and provides for almost $90 \%$ of rural household energy need. Dependence on wood fuel is among the contributors of deforestation exacerbating the country's greenhouse emissions. A study by Marigi (2017) has estimated that typical rural Kenyan family consumes about $11 \mathrm{~kg}$ of firewood daily, generating approximately $20.57 \mathrm{~kg}$ of carbon dioxide.

There is extensive research showing that traditional cooking stoves that utilize biomass contribute to a wide range of negative impacts on human health, air quality, and climate change. Although many agencies including World Health Organizations (WHO) recommend adoption of ICS in rural settings where cleaner sources of cooking are not available, to reduce indoor pollution, many communities are still challenged with appropriate stove selection, and sustained stove adoption and use. The efforts to better understand and provide solutions to this have faced several challenges. The challenges include matching new technologies with local socioeconomic conditions and cooking culture and designing comprehensive measurement strategies to effectively diagnose success or failure of these improved stoves.

Kenya is one of the countries where a great deal of research has continued to promote the adoption of improved cooking stoves in Kenya. Improved cookstoves have been recommended by many researchers as efficient and effective biomass-fuel stoves that reduce chronic obstructive pulmonary diseases, lung cancer, low birth weight, and premature mortality (Clark et al. 2009). In western Kenya, improved stoves were projected as human health survival especially to the children. The researchers promoted improved cookstove adoptions in the area with a goal to increase human survival through improving air, reducing disease, saving time and money, and reducing environmental degradation. Exposure to indoor air pollution has been blamed to poor human health especially women and both infants and small children who are present near the cooking site. Ezeh and others (2014) noted a $0.8 \%$ of neonatal deaths, $42.3 \%$ of post-neonatal deaths, and $36.3 \%$ of child deaths occurred in household using solid fuels for cooking; $70 \%$ of the deaths occurred in rural areas. Some of the promotional strategies in attempt to increase adoption of improved cooking stoves have included linking the prevalence of respiratory-related illness among household members to the indoor pollution associated with the use of firewood. These strategies have advocated for the use of improved cooking 
stoves as cleaner alternatives to mitigate indoor pollution, and research designs have revolved around generating empirical evidence to link adoption with improved health outcomes. Pilishvili et al. (2016) work showed that ICS were effective in reducing household air pollution leading to considerable acceptability in rural western Kenya. Also, the work by Silk and others (2012) work sought to increase adoption of locally produced ceramic cookstove in rural Kenyan household. Also, the work by Clark and others (2009) showed positive health impacts among women related to reduced indoor pollution following adoption of ICS.

Other researchers have attempted to leverage on ICS potential benefits of reducing indoor pollution to increase acceptability and adoption. Recent years have embraced much broader advocacy on the wider socioenvironmental benefits of ICS to entice communities' adoption. Jeuland and Pattanayak (2012) have investigated the benefits versus the costs of improved cook stoves in relation to wider implications of variability in health, forest, and climate impacts. The authors argued that adoption of ICS had broader benefits that included health improvement, time saving for households, preservation of forests, and reduction in emissions that contribute to global climate change. The authors concluded that households often find the improved cook stove technology to be inconvenient or culturally inappropriate resulting in disappointing uptake.

Liyama and others contend that ICS reduce deforestation and greenhouse gases that increase global warming leading to climate change. Other researchers who have explored related environmental benefits of ICS adoption include, Kiefer and Bussmann (2008) and Jeuland and Pattanayak (2012). These researchers have evaluated the benefits and costs of ICS on health, forests, and climate impacts, concluding that improved stoves provide improved health and time saving in household, preserve forests and related ecosystem and reduce emissions contributing to global climate change. On the contrary, biomass burning in inefficient cookstoves negatively impact on household level, community and national level, and regional and global level.

Both collecting and combustion of solid fuels used in household levels affects women and girls. Njenga et al. (2017) emphasize that scarcity of firewood forces women and girls to travel long distances looking for the commodity. The authors' claim has become part of the advocacy for improved cookstoves to ensure women could invest time in economically productive activities. Additionally, collecting and carrying is life threatening as women can suffer body injuries, rape, or attacked by wild animals (Njenga et al. 2017). Unsustainable firewood harvesting contributes to forest degradation, further contributing to loss in a nation's carbon sink. According to Loo et al. (2016), demand of biomass fuels is threatening forest cover given the rising demand for the commodity by schools, hotels, industries, among others, hence high emissions leading climate change.

The progress of achieving large-scale adoption and use of ICS has been slow and literature has little information of the slow uptake. Some researchers have contended that cost is not a barrier to adoption pointing that adoption and use of improved stoves is low even when households have given ICS without a charge. A study done in Peru, in 26 villages, only $46 \%$ of households used improved stoves given free of 
charge (Adrianzén 2010). The findings left the authors puzzled by the difficulties communities faced adopting ICS technologies given the benefits such as reducing household health burden related to indoor air pollution (Ezeh et al. 2014).

\section{Materials and Methods}

A questionnaire with open- and closed-ended questions was used to collect data from a sample of 54 women from the rural parts of Laikipia and Machakos County in 2018. In most rural areas in Kenya, cooking is one of the main chores for women. Data collected included energy sources for cooking for households, perceptions of health and environmental problems associated with the use traditional cooking stoves, extent of use of ICS, perceptions of socioenvironmental benefits, perceived importance to a household portfolio of the different sources energy for cooking, individual perceptions related to future trends of the usage of the different sources of energy for cooking, and perceived barriers to the adoption of ICS. Additional questions included sociodemographic information. Descriptive statistics were used to summarize data. Inferential statistics (independent t-test) were used to examine relationships between variables by region.

\section{Results and Discussion}

\section{Sociodemographic Characteristics of the Sample}

Table 1 below summarizes sociodemographic characteristics of the sample. Majority of the respondents in both counties were aged between 18-29 and 30-59 years. These are the productive age groups in a country and reliance on firewood collection and cooking takes away time that could be invested in productive economic engagements. The average household size for Machakos was 5.77, while that of Laikipia was 4.77. The differences in household size, number of primary school going children, and number of children under 5 years old between Machakos and Laikipia were statistically significant, $\mathrm{t}(52)=2.45, p<0.05, \mathrm{t}(52)=-4.74$, $p<0.05$, and $\mathrm{t}(52)=-6.06, p<0.05$, respectively.

\section{Source of Energy for Cooking and Perceived Importance of Various Sources by Study Sites}

Majority of the respondents from the two study areas mentioned relying on both firewood and charcoal for cooking. The researchers further probed sources of energy for cooking. Majority cited that firewood was collected from nearby woodland resources (see Fig. 1). However, majority also mentioned buying both firewood and charcoal. During 1960s, majority of Kenya's rural population probably never imagined of a time when obtaining firewood would cost money, hence purchasing 
Table 1 Sociodemographic characteristics of the sample

\begin{tabular}{|c|c|c|c|}
\hline Variable & Category & $\begin{array}{l}\text { Machakos } \\
\%(\text { Mean } \pm \text { SD })\end{array}$ & $\begin{array}{l}\text { Laikipia } \\
\%(\text { Mean } \pm \mathrm{SD})\end{array}$ \\
\hline \multirow[t]{4}{*}{ Age } & $18-29$ & 15 & 25 \\
\hline & $30-59$ & 77 & 75 \\
\hline & $\begin{array}{l}60 \text { or } \\
\text { above }\end{array}$ & 8 & 0 \\
\hline & $18-29$ & 15 & 25 \\
\hline \multirow[t]{5}{*}{ Marital status } & Married & 77 & 57 \\
\hline & Single & 12 & 21 \\
\hline & Separated & 4 & 0 \\
\hline & Windowed & 8 & 21 \\
\hline & Married & 77 & 57 \\
\hline Average household size & & $5.77 \pm 0.54$ & $4.64 \pm 1.72$ \\
\hline Average number of school-going children & & $1.65 \pm 1.9$ & $3 \pm 1.22$ \\
\hline $\begin{array}{l}\text { Average number of children under } 5 \text { years } \\
\text { old }\end{array}$ & & $0.81 \pm 0.83$ & $2.46 \pm 0.88$ \\
\hline
\end{tabular}

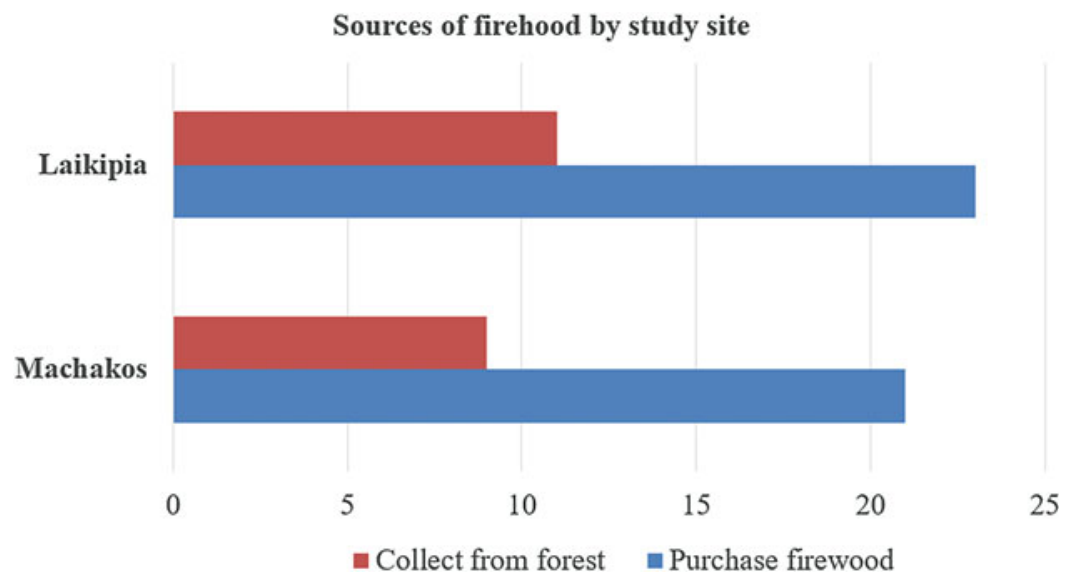

Fig. 1 Households' sources of firewood. (Source: Survey data)

firewood once regarded an abundant and free resource highlights that over the years sources of firewood have declined to the point that households must purchase the commodity. On average, respondents from Machakos spend $88.5(S D=20.72)$ per bundle of firewood, while those from Laikipia spend $237(S D=50.00)$ on firewood. On average, respondents from Machakos spend $48.40(S D=4.95)$ on charcoal, while those from Laikipia spend $57(S D=5.39)$. The differences in households' expenditures on both firewood and charcoal between the two counties were statistically significant, $\mathrm{t}(\mathrm{df})=9.97, p<0.05$ (firewood), $\mathrm{t}(\mathrm{df})=8.90, p<0.05$ (charcoal). Respondents were asked how much money they spend on a month to meet expenses related to energy for cooking. Results revealed that showed that 
on average, households in Machakos spend $2475(S D=35.54)$ compared to 875 $(S D=144)$ in Laikipia. The differences in monthly expenditures between the two counties were statistically significant, $\mathrm{t}(\mathrm{df})=6.67, p<0.05$.

Continued reliance on firewood for cooking can be attributed to affordability and availability. In Laikipia, communities have access to adjacent forests for firewood. Moreover, the increase in vendors using motorcycles to ferry firewood further plays role in providing the commodity to households. Mobile vendors make it more convenient for households to save time that would otherwise be spent collecting firewood. It appears from the results obtained that firewood is a little more costly in Laikipia than in Machakos. This is probably because besides cooking, households in Laikipia also use firewood and charcoal for warming the house especially in the evening and during the cold season. It is also probable that most charcoal used in Laikipia is transported from distant sources, unlike in Machakos where residents rely on adjacent counties, Makueni and Kitui for the commodity.

Researchers asked respondents "who in the household was responsible for collecting firewood." Results obtained showed that women and children were involved in collecting firewood for cooking; however, men were largely involved in the collection and sale of firewood (see Fig. 2). Respondents were asked who in the household was responsible for paying for charcoal and firewood. Machakos, women households were responsible for meeting monthly energy expenses, while in Laikipia, men played that role. Few respondents mentioned children; these are probably elderly women who rely on their children or grandchildren for financial support.

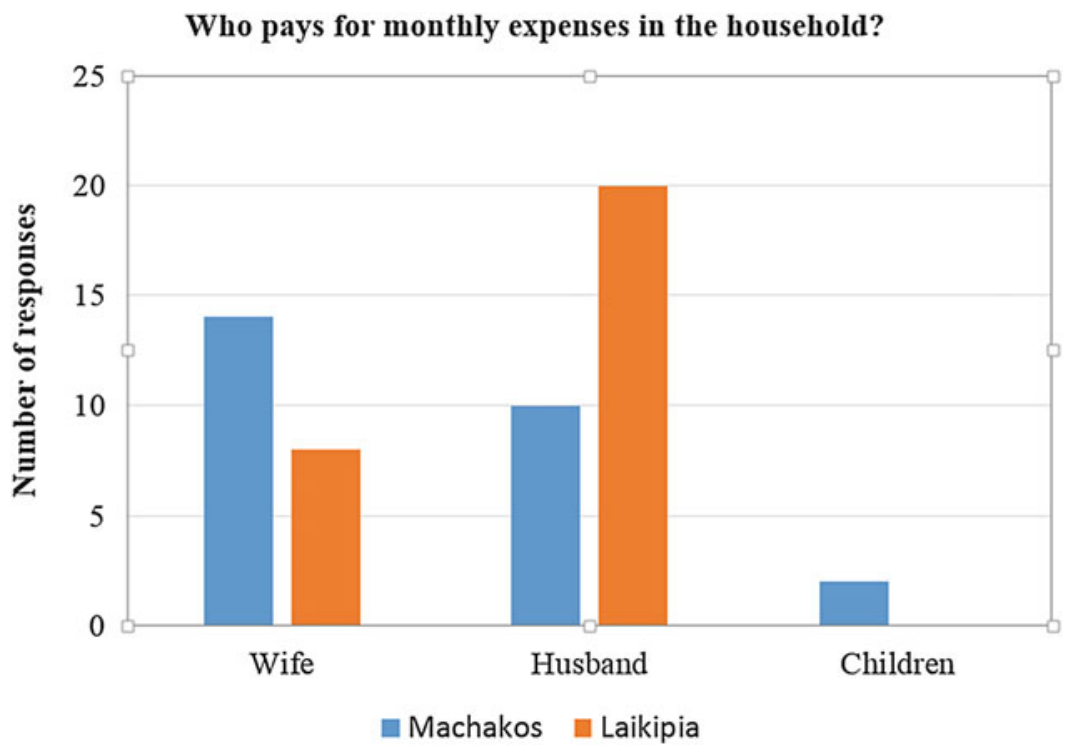

Fig. 2 Persons in the household responsible for paying household expenses related to energy used 
In Laikipia, much of the responsibility of fetching firewood belongs to the wife; according to the findings of this study, it was observed that $78 \%$ of household expenses on firewood were done by men. Men in the region are involved more in forest destruction activities that include logging and charcoal burning. Sourcing of firewood and charcoal is expensive and all household budget for it. In Laikipia, majority of husbands play a significant role in meeting household needs mainly because they participate in preparing them (firewood and charcoal), transportation, and in some instances marketing. Another observation is that they buy firewood in larger quantities in form of sacks and large firewood bundles attracting higher value covered by majority of husbands. To some husbands, it is a full-time business.

In Machakos, it appears that the responsibility paying for fuel is perceived as feminine responsibility; majority of respondents at $53.8 \%$ admitted that it is the responsibility of the wife, $38.5 \%$ said it is husband's responsibility, while only $7.7 \%$ said it is the children who pays for fuel expenses.

Several researchers have noted the gendered division of labor when it comes to firewood collection and provisioning at the rural settings. Edelstein et al. (2008) have pointed on the gendered politics of firewood, contending that women have to transverse long distances to gather firewood. The implication is that women spend more time looking for energy sources instead of engaging in productive economic activities. Respondents were asked what other challenges beside increasing scarcity, women encountered when looking for firewood. One challenge that was frequently mentioned were increasing number of conflicts. All respondents from Laikipia reported experiencing conflicts associated with firewood collection. Conflicts over firewood may take a variety of forms, for instance, some sources are as a result of youth in the collection and sale of firewood for income. Other conflicts may be related to emerging rising demand from hotels, schools, small industries, and hospitals.

Table 2 summarizes respondents' perceptions in relation to the importance of various sources of energy for cooking in both Counties. The study observed that the main sources of energy for cooking is firewood and charcoal. This indicates rural population rely on trees for source of energy for cooking and warming, and therefore, there is need for energy saving technologies in both counties.

Results revealed that cow dung is not an important source of energy for cooking in Laikipia (90\%) but an important a source of energy for cooking in Machakos (28\%). Crop waste is not a source of energy in Laikipia (100\%), but somehow a source in Machakos (42\%). Due to high rate of population, Machakos may have faced acute deforestation situation, where in some places only cow dung and crop waste are the only source of energy for cooking and warming. Silk et al. (2012) pointed out that where fuel becomes expensive, the disadvantaged population turns to the available cheap ones including plastics.

Findings showed that also saw dust was somehow a source of energy in both counties: Machakos 38\%, while Laikipia $17.8 \%$. Kerosene is used for cooking in both counties: Machakos $80.7 \%$, while Laikipia $100 \%$. Kerosene is a common fuel even in rural small towns and can be purchased using $<50$ shillings. Handling kerosene stoves is easy despites its high production of particulate matter and carbon 
Table 2 Perceived importance various energy sources for cooking by study site

\begin{tabular}{l|l|l|l|l}
\hline \multirow{2}{*}{$\begin{array}{l}\text { Cooking energy } \\
\text { source }\end{array}$} & Region & $\begin{array}{l}\text { Not } \\
\text { important } \\
(\mathbf{\%})\end{array}$ & $\begin{array}{l}\text { Somewhat } \\
\text { important } \\
(\%)\end{array}$ & $\begin{array}{l}\text { Very } \\
\text { important } \\
(\%)\end{array}$ \\
\hline \multirow{2}{*}{ Cow dug } & Machakos & 72 & 12 & 16 \\
\cline { 2 - 5 } & Laikipia & 90 & 0 & 0 \\
\hline \multirow{2}{*}{ Crop waste } & Machakos & 58 & 31 & 12 \\
\cline { 2 - 5 } & Laikipia & 100 & 0 & 0 \\
\hline Firewood dust & Machakos & 58 & 39 & 4 \\
\cline { 2 - 5 } & Laikipia & 36 & 18 & 4 \\
\hline \multirow{2}{*}{ Charcoal } & Machakos & 4 & $\mathbf{3 5}$ & $\mathbf{6 6}$ \\
\cline { 2 - 5 } & Laikipia & 0 & $\mathbf{3 2}$ & $\mathbf{6 8}$ \\
\hline \multirow{2}{*}{ Kerosene } & Machakos & 0 & $\mathbf{3 9}$ & $\mathbf{6 2}$ \\
\cline { 2 - 5 } & Laikipia & 0 & 58 & 23 \\
\hline \multirow{2}{*}{ LPG } & Machakos & 19 & 46 & 54 \\
\cline { 2 - 5 } & Laikipia & 0 & 27 & 42 \\
\hline \multirow{2}{*}{ Biogas } & Machakos & 31 & 89 & 11 \\
\cline { 2 - 5 } & Laikipia & 0 & 46 & 0 \\
\hline
\end{tabular}

monoxide which endangers human health. A study by Pilishvili et al. (2016) observed that additional hour of kerosene use was associated with 5\% increase in mean kitchen particulate matter. LPG is also a common source of energy in Machakos (69.2) and Laikipia (100\%) as well as biogas recording $82.1 \%$ in Laikipia and $46.1 \%$ in Machakos.

\section{Cow Dung and Crop Waste}

In both regions, cow dung and crop waste according to the research indicate that majority saw it as not important. However, Machakos $16 \%$ indicated that it is a very important energy source. Machakos study indicates that some household of study have cleared most of the trees for other development activities. Therefore, the only available cheap fuel source is cow dung and crop waste which contributes high rate of indoor air pollution. This implies that higher health problems on both women and children in Machakos than in Laikipia. In Machakos, over 80\% of the households has a cow and they live within the homestead; therefore, the energy source is always available but only preferred in time of extreme need. Promotion of improved cook stove in Machakos started many years back led by Nongovernmental organizations and the government. It therefore implies that majority of homes have an improved stove that easily used dried cow dung to cook. The climate in Machakos favors quick drying of the dung hence less time is needed to prepare it. The fact that $16 \%$ noted it as very important implies that the population entirely depends on cow dung for cooking. Use of crop waste is seasonal and fuel energy sources like maize, sorghum, and grass stalks are mainly available after harvest, therefore is an important energy source in Machakos. The pattern shows that those who regard it as very important 
are less than those who perceive it as somewhat important. It therefore implies that there is a certain population that entirely depends on crop waste for cooking and this indicates the possibilities of having serious biomass smoke-related health cases in Machakos than in Laikipia (Silk et al. 2012). In Laikipia, cow dung and crop residue are not important at all, since there are other better easily available energy choices. Also, the proximity to the forest enhances accessibility to the energy sources.

\section{Kerosene, LPG, and Biogas}

Kerosene as an energy source was noted as more important in Laikipia than in Machakos. This could be attributed to cost and availability since interviewed Laikipia residents seem more sound economically and price determines energy source to use (Silk et al. 2012). Again, one must have a stove designed to use kerosene. This therefore implies increased kerosene related indoor particulate matter pollution according to Pilishvili et al. (2016). In Laikipia, distribution networks for kerosene are more improved than Machakos, hence underlining the product mix concept that states that there is a correlation between products availability and consumption. Few Machakos women (23\%) may be relying totally to Kerosene as a source of cooking, while for the rest, kerosene is mostly for light and biomass fuel for cooking. The study is from rural Machakos where few able household use electricity for light. Kerosene for cooking, compared to biomass fuel, is expensive for rural poor households. This could be the reason for low use of kerosene in Machakos.

LPG was noted as very important in Machakos than in Laikipia. However, those who stated as somehow important were at $89 \%$ meaning that they consider it necessary but it is not the only solution to energy needs. The price of a product like LPG determines the offering which the customers are willing to give to buy the targeted product. The importance attached to it in Machakos may imply that it is used for major cooking and different affordable packaging sizes in the market attracts many customers. In Laikipia, it seems the energy source LPG is used for light cooking mainly in the morning and late in the evening.

Biogas was noted as very important in Machakos as compared to Laikipia. However, on average, biogas was noted to be used more in Laikipia. This could be attributed by the fact that it requires relative huge investment to establishing a zero-grazing unit.

\section{Women's Perceptions of Health Risks Associated with Reliance on Firewood}

Participants were asked to list what they perceived as the health risks associated with the use of traditional firewood stoves for cooking. The lists of mentioned problems were entered in an Excel spreadsheet, and a tally was done to generate a graph summarizing frequently mentioned health risks/illnesses. Results obtained showed that the frequently mentioned health risks, in order of the most to least frequently mentioned health risks included: chest pain, sneezing, irritating eyes, breathing problems, and congestion of throat. Figure 3 summarizes the frequency of mention 


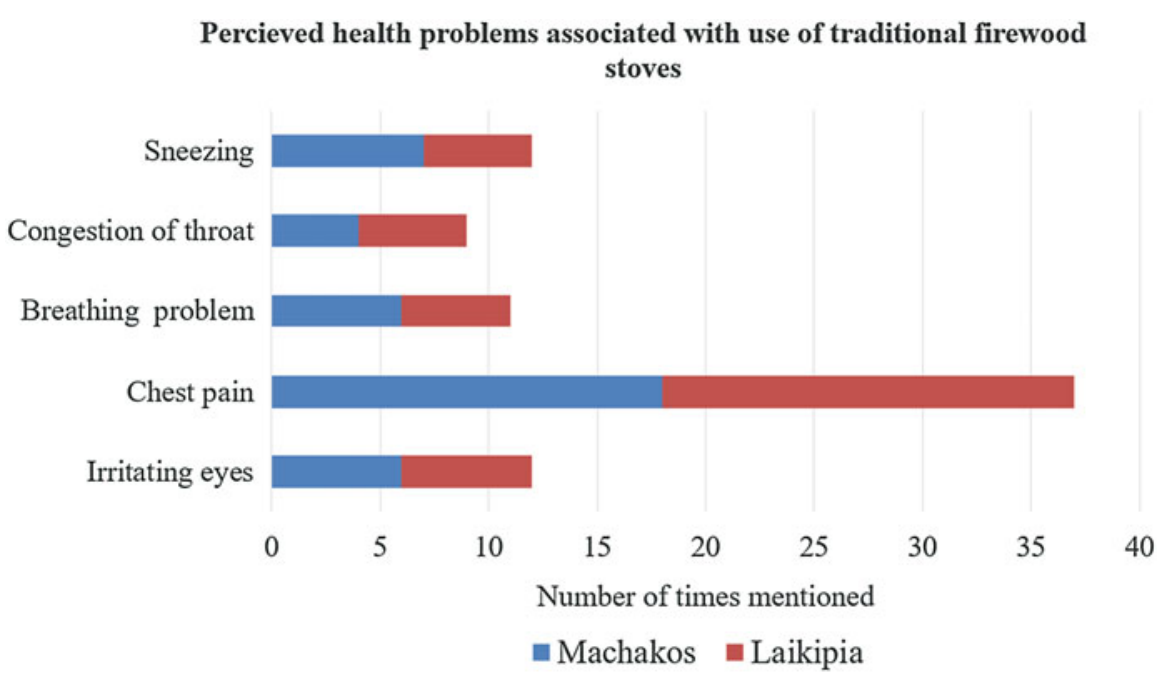

Fig. 3 Perceived health risks associated with the use of firewood traditional stoves for cooking

of the different health risks by respondent study site. Majority of women described chest pain to be a serious health risk. This was consistent across the two study sites. The secondly mostly mentioned health risk was sneezing, again patterns of the number of women describing sneezing problems were consistent across the two study sites. The third most mentioned health risk was eye irritation, and again, patterns of the number of women describing eye irritation problems were consistent across the two study sites. The least frequently mentioned health risk was congestion of throat, and again patterns of the number of women describing congestion of chest problems were consistent across the two study sites. Health risks mentioned can be summarized as respiratory and eye irritation illnesses. All these illnesses are associated with indoor pollution due to smoke and soot emanating from the burning of firewood. ICS are reported reduce indoor pollution related to smoke, and consequently, reduce the illnesses mentioned by the respondents in this study. Where adoption of ICS is challenge, some development agencies have innovated smoke hoods as options for reducing smoke, hence reduced levels of indoor pollution.

\section{Perceived Future Trends on Use of Various Forms of Energy Sources}

Respondents were asked what they perceived to be future trends on use of various forms of energy sources. Table 3 summarizes participants' responses by county. Results showed that almost all the respondents from Laikipia (100\%) perceive the use of firewood to remain in the upwards trends $(96.4 \%$ ) compared to $46 \%$ from Machakos county. It is unclear what might inform this sort of perceptions. Respondents' perceptions correspond to the expected trends of firewood use in the coming decades, one would anticipate potential decline in negative impacts on forest cover further undermining climate mitigation measures and rural resilience (Njenga et al. 2017). 


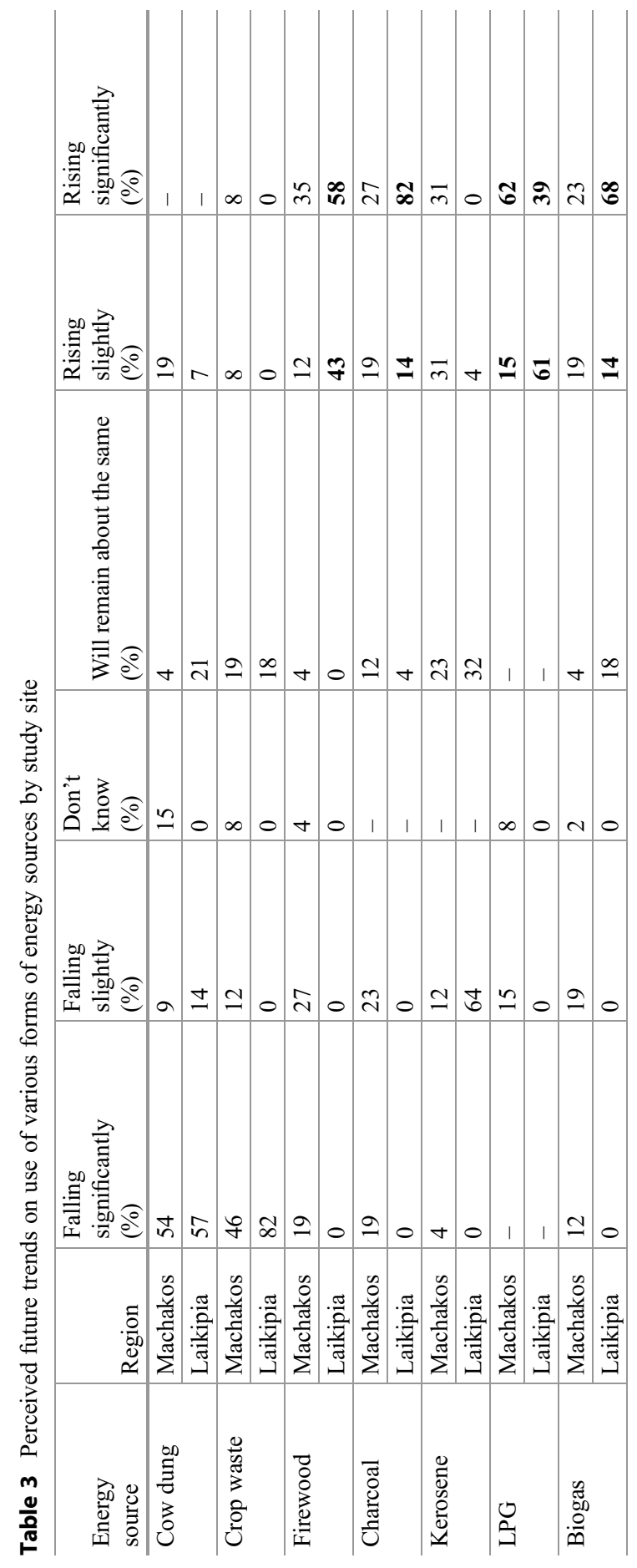


Participants from Laikipia, however, anticipate an upward trends in the use of LPG (100\%). In addition, majority of respondents from Laikipia (82\%) anticipate an upward trend in the adoption of biogas, compared to only $42.3 \%$ in Machakos county. LPG provides a capability to prepare meals in a shorter time, especially children's foods (Khadilkar 2015). Market for LPG have continued to provide attractive cylinder sizes affordable to low-income clientele. Also, majority of the women have an appeal for LPG as a clean energy for cooking, especially where mothers are accompanied by their children during cooking. Abundant crop waste, largely wheat and maize to support zero grazing is probably the reason for the perceived rise in biogas adoption in Laikipia.

Respondents from Machakos anticipate an upward trend in the use of kerosene. Besides cooking, kerosene also used for lighting in most rural homes in Machakos. Women overwhelmed with domestic chores prefer lighting a kerosene stove especially for lighter meals. Machakos has limited availability of crop residue and farmbased biomass. In Laikipia, respondents perceive a decline on the future use of kerosene for cooking. It is unclear what might inform this anticipation.

LPG use in Machakos is likely to rise significantly due to the ongoing government subsidy and use of flexible packaging containers. In Machakos, the current generation of population is constructing modern houses which have no kitchens to light firewood or charcoal giving preference to clean energies like LPG and biogas. In both counties, family sizes are becoming smaller with an average of two children, hence demand for heavy cooking will cease with time and demand for clean affordable energy like LPG and biogas will rise.

\section{Perceived Barriers to Adoption of Improved Cooking Stoves}

Respondents were asked on perceived barrier to adopt ICS. Table 4 summarizes responses by county. Results reveal that improved cook stoves are perceived to be costly compared to traditional stove. In both counties, Machakos (57.7\%) and Laikipia (57.2) studies, cost was perceived to be a barrier to owning ICS. Some of these cook stoves are unaffordable by rural women especial those with no/little income. Jeuland and Pattanayak (2012) concur with this point when their study argued that women find it expensive to pay for the stove and self-learning of length of time to understand how properly to use the new technology.

Availability of charcoal affects adoption of ICS more in Laikipia (77.6\%) than in Machakos (42.3\%). The study shows that cost of charcoal affects ICS adoption in Laikipia (96.4\%) more than Machakos (42.3\%).

Stove design is probably not perceived as barrier in Machakos (34.4\%); however, majority of the women from Laikipia $(60.7 \%)$ seems to suggest design as problem. Stove designs acceptance depends on the provision benefits of cooking styles and needs of a given locality (Khadilkar 2015). Masera et al. (2007) cited the difficult of using some stove design to prepare traditional foods in Mexico. Also accepting a design means being able to use and repair. Therefore, improved cook stove may not be meeting the traditional needs of cooking in Laikipia. Also, low rate of literacy in 


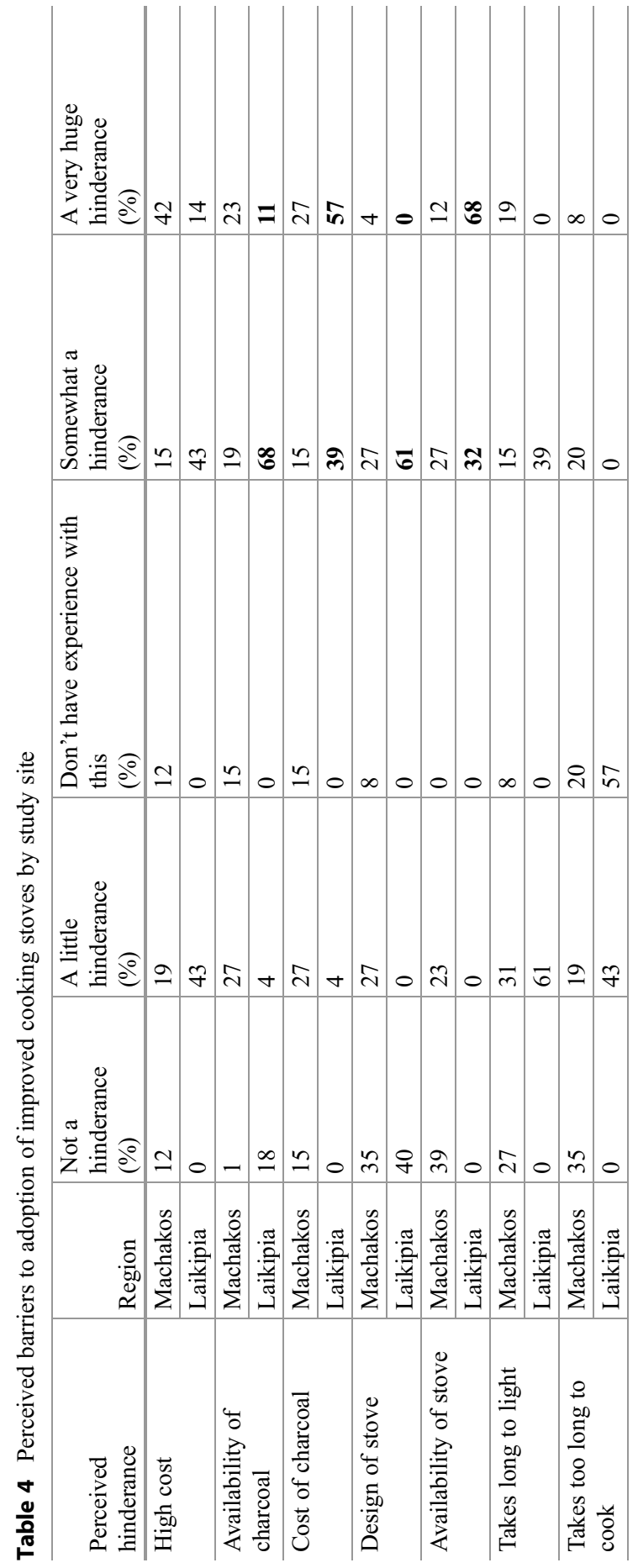


the society may not be receptive of new technology ideas. Improved cook stoves availability is a barrier to own one in Laikipia county (100\%), while in Machakos County (38.5\%) is not an hinderance. Lighting ICS is not termed as a big issue in ICS ownership in both counties Machakos (30.8\%) and Laikipia (60.1\%). Cooking food using ICS in Machakos (34.6\%) is not a barrier of owning one, but in Laikipia majority $(57.1 \%)$ reported that they lacked experience of time taken in cooking. Sometimes new technologies are not accepted immediately because of the way users fear to change their behavior of cooking, other stove increase fuel consumption or increase time spend in cooking (Jeuland and Pattanayak 2012).

\section{High Cost}

In Machakos, high cost of stoves was noted as a major hindrance at $42 \%$ in stoves adoption. Today, due to challenges in livelihood income, every cent spent in a family counts and expenditure is based on priorities like paying school fees and buying food for the family. Possible reason could be that the stoves are never budgeted for and in some cases, it is perceived as luxurious and not a solution to indoor pollution. Most promoters of the stoves ask for prompt payment at once making them unaffordable. As mentioned earlier, domestic costs in Machakos are met by women with little or no support from men. Therefore, even if the stoves are sold at a discounted rate, they will always seem expensive. Also, the rural women may lack adequate information/awareness of benefits of improved cook stoves. ICS promoters in most cases mention short-term benefits such as saving firewood/charcoal but forget long-term benefits such health benefits. With this, concerned population end up missing crucial information especially health problems of children and mothers. The implication is that the adoption rate will be low, and firewood and biomass use continue creating negative impact to the environment.

\section{Availability of Charcoal}

This is also a major hindrance when it comes to stoves adoption in Machakos. Even though improved cook stove uses less charcoal, it must be of high quality and size to avoid smoking, and this is a challenge. In Machakos, charcoal is produced illegally, outside Charcoal Producer Association (CPA), hence inadequate in the market. For the last two decades, illegal charcoal production and land for agriculture degraded trees in rural Machakos and affected the availability of charcoal. The concept of demand and supply applies, if charcoal is not adequately available, it becomes expensive.

\section{Cost of Charcoal}

The reason for low adoption in Laikipia is noted as the cost of the charcoal at 57\%. Possible reasons are due to the existence of other sources of energy which are cleaner and cheaper. Marketing of charcoal in Laikipia is mainly in bags and this to many is a huge cost.

\section{Design of the Stove}

In Machakos, the design of the stove was noted as a hindrance. Possible reasons could be the fact that stove design determines efficiency of cooking, size of cooking pot too, and the type of food to cook. Most of ICS are imported to Machakos rural areas and may be 
the designs do not meet the cooking needs of Machakos rural women. Again, some improved designs need specialist for repair which require funds when compared with three stone. Further, energy saving stoves are designed to save charcoal use, therefore their efficiency is lower and cannot be compared to the three stone firewood stoves. Stove design also influences the time taken to light the stove. According to the pattern from the research, stove design is a bigger hindrance in Laikipia. Availability of firewood and the need to warm houses during cold season are possible reasons. Improved cook stoves are made of vermiculite stone to reduce heat loss hence they do not warm the houses. The implication is that even if the stoves are acquired, they are never adequately used.

\section{Availability of the Stove}

This seems to be a huge hindrance in Laikipia, and the all the interviewees fell in the category of somewhat a hindrance $(32 \%)$ and some stated it is a very huge hindrance (68\%). Marketing of improved stoves is a huge business in the energy sector. Private companies have invested a lot and they need return on investment. Distribution of improved cook stoves is low in regions with adequate energy sources like charcoal and firewood, since few people buy them. This translates to low adoption rate and increased forest destruction to sustain the preferred energy sources.

\section{Takes Too Long to Light}

Respondents from Machakos (205\%) seem to find the time it takes to light ICS to be problematic. Women engaged in household activities value time management. Due to heavy responsibilities within domestic arena, women are assisted to light stoves by their children. But children may face challenges lighting new designs. The comparison is based on traditional stoves. Lighting an improved stove requires a bit of skills that may be a challenge to the elderly. The problem is exacerbated by a lack of special gel for lighting cook stoves. To hasten lighting ICS, majority of the households use kerosene or old newspapers which adds to the cost/expenses of ICS for a household. The implication is that regular use of the stove does not happen.

\section{Takes Too Long to Cook}

Observed responses by study sample from Machakos county might be due to mostly preferred traditional diet in this region. Generally, improved cook stove is meant for light cooking. Quality of charcoal in Machakos is a factor since the best charcoal is from indigenous trees classified as hard wood which is rare in the region. Traditional foods are potentially most preferred due to economic challenges; however, cooking traditional dishes takes relatively longer compared to modern dishes. This has implications since ICS are relatively less used particularly among the elderly women. 


\section{Lessons Learned, Study Limitations, and Recommendations for Future Research}

Even though access to cheaper sources of firewood continue to diminish, use of firewood for cooking still remains the most accessible form of energy for cooking in Kenya's rural areas. This trend is likely to persist in the next coming decade. Women are aware of the health risks associated with reliance on this source of energy. Given that low adoption of ICS as alternative methods of cooking may persist, there is need for interventions that reduce indoor pollution problems associated with continued reliance on firewood. This study was based on participants sampled from two counties; future research may need to include a representative mix of regional ethnic groups in Kenya. The variability on barriers to adoption highlight the need for a highly contextualized design and production of ICS to enhance adoption in culturally diverse contexts. Future research may need to explore the possibility of participatory design in which members of rural communities participate in designing ICS that appeal to their cultural preferences. This potential can be explored via the technical vocational institutions now almost distributed in every county in Kenya.

\section{Conclusion}

Citizens in Kenya's rural areas are aware of the health and negative socioenvironmental consequences of relying on traditional unimproved firewood cooking stoves. However, there is still an inertia for continued dependence on firewood in the coming decades. Drivers of the perceived upward trends are a result of interaction of many factors. Barriers for adoption of ICS vary according to cultural taste and perceptions of ICS. Diminishing cheaper sources of firewood due to rapid population growth resulting to subsequent smaller land parcels imply future vulnerabilities by rural households as the cost of purchasing firewood is likely to keep rising, posing additional economic burden to households in terms of money spent purchasing firewood, but also on treatment of illnesses associated with indoor pollution from burning firewood. There is need to promote agroforestry as a potential option for meeting anticipated upward trends in demands for firewood to ensure resilience of rural livelihoods and sustainability of current efforts to improve the forest cover in Kenya.

\section{References}

Adrianzén M (2010) Improved stove adoption, firewood consumption and housewives' health: evidence from the Peruvian Andes. http://mitsloan.mit.edu/neudc/papers/paper_289.pdf. Accessed 12 Dec 2019

Boampong R, Phillips MA (2016) Renewable energy incentives in Kenya: feed-in-tariffs and rural expansion. University of Florida, Gainesville 
Clark ML, Pell JL, Burch JB, Nelson TL, Robinson MM, Conway S, Bachand AM, Reynolds SJ (2009) Impact of improved cookstoves on indoor air pollution and adverse health effects among Honduran women. Environ Health Res 19(5):357-368

Dickinson KL, Kanyomse E, Piedrahita R, Coffey E, Rivera IJ, Adoctor J, . . Hayden MH (2015) Research on Emissions, Air quality, Climate, and Cooking Technologies in Northern Ghana (REACCTING): study rationale and protocol. BMC Public Health 15(1):126

Edelstein MA, Pitchforth E, Asres G, Silverman M, Kulkarni NS (2008) Awareness of health effects of cooking smoke among women in the Gondar region of Ethiopia. BMC Int Health Hum Rights 8:1-7

Ezeh OK, Agho KE, Dibley MJ, Hall JJ, Page AN (2014) The effect of solid fuel use on childhood mortality in Nigeria: evidence from the 2013 crosssectional household survey.Environ Health. 13:113

Jeuland MA, Pattanayak SK (2012) Benefits and costs of improved cookstoves: assessing the implications of variability in health, forest and climate impacts. PLoS One 7(2):e30338

Khadilkar PD (2015) Capability approach-based evaluation of a biomass cook-stove design. Curr Sci 109(9):1601

Kiefer S, Bussmann RW (2008) Household energy demand and its challenges for forest management in the Kakamega area, western Kenya. Ethnobot Res Appl 6:363-371

Loo J, Hyseni L, Ouda R, Koske S, Nyagol R, Sadumah I, ... Stanistreet D (2016) User perspectives of characteristics of improved cookstoves from a field evaluation in Western Kenya. Int J Environ Res Public Health 13(2):167

Marigi SN (2017) A stochastic investigation of solar energy application potential in rural households of Kenya and the associated environmental benefits. J Geosci Environ Prot 5(04):1

Masera O, Edwards R, Arnez CA, Berrueta V, Johnson M, Bracho LR, ... Smith KR (2007) Impact of Patsari improved cookstoves on indoor air quality in Michoacán, Mexico. Energy Sustain Dev 11(2):45-56

Ndegwa G, Breuer T, Hamhaber J (2011) Woodfuels in Kenya and Rwanda: powering and driving the economy of the rural areas. Rural 45(2):26-30

Njenga M, Mahmoud Y, Mendum R, Iiyama M, Jamnadass R, De Nowina KR, Sundberg C (2017) Quality of charcoal produced using micro gasification and how the new cook stove works in rural Kenya. Environ Res Lett 12(9):095001

Pilishvili T, Loo JD, Schrag S, Stanistreet D, Christensen B, Yip F, ... Bruce N (2016) Effectiveness of six improved cookstoves in reducing household air pollution and their acceptability in rural Western Kenya. PLoS One 11(11):e0165529

Silk BJ, Sadumah I, Patel MK, Were V, Person B, Harris J, ... Quick RE (2012) A strategy to increase adoption of locally produced, ceramic cookstoves in rural Kenyan households. BMC Public Health 12(1):359

Osita Kingsley Ezeh, Kingsley Emwinyore Agho, Michael John Dibley, John Joseph Hall, Andrew Nicolas Page, (2014) The effect of solid fuel use on childhood mortality in Nigeria: evidence from the 2013 cross-sectional household survey. Environmental Health 13 (1)

Open Access This chapter is licensed under the terms of the Creative Commons Attribution 4.0 International License (http://creativecommons.org/licenses/by/4.0/), which permits use, sharing, adaptation, distribution and reproduction in any medium or format, as long as you give appropriate credit to the original author(s) and the source, provide a link to the Creative Commons license and indicate if changes were made.

The images or other third party material in this chapter are included in the chapter's Creative Commons license, unless indicated otherwise in a credit line to the material. If material is not included in the chapter's Creative Commons license and your intended use is not permitted by statutory regulation or exceeds the permitted use, you will need to obtain permission directly from the copyright holder.

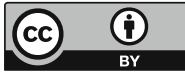

